\title{
CORRECCIÓN Y RACIONALIDAD EN EL DISCURSO JURÍDICO
}

\author{
CORREÇÃO E RACIONALIDADE NO DISCURSO JURÍDICO
}

CORRECTION AND RATIONALITY IN THE LEGAL DISCOURSE

\section{José Manuel Cabra Apalategui}

Doutorado em Direito pela Universidade Carlos III de Madrid (Instituto Bartolomé de las Casas de Direitos Humanos) e professor de Filosofia do Direito na Universidade de Málaga.

\section{Resumo}

Os desenvolvimentos da Teoria do Discurso nos últimos anos deram origem a diferentes interpretações que oscilam entre o construtivismo e o realismo, dependendo da interpretação da relação entre os conceitos de verdade e correção moral, por um lado, e aceitabilidade racional, por outro. A interpretação realista ou não reducionista proposta, entre outras, por Cristina Lafont, deu origem a um fecundo debate que se estende não apenas à teoria da verdade, mas também à ética discursiva. Neste artigo, pretendo analisar as consequências de tal interpretação para a teoria do discurso jurídico.

Palavras-chave: Construtivismo; realismo; objetividade; discurso jurídico; Aarnio; Alexy.

\begin{abstract}
Developments on the Theory of Discourse in recent years have given rise to different interpretations of it that swing between constructivism and realism, depending on the interpretation of the relation between the concepts of truth and moral corretness, in the one hand, and rational acceptability, on the other hand. The realist or non-reductionist intepretation proposed, among others, by Cristina Lafont has originated
\end{abstract}


a fruitful debate that extends not only to the theory of truth, but also to discursive ethics. In this paper, I pretend to analyze the consecuences of such an interpretation for the theory of legal discourse.

Key words: Constructuvism, realism, objectivity, legal discourse, Aarnio, Alexy.

\section{Resumen}

La evolución de la teoría del discurso en los últimos años ha propiciado diversas interpretaciones, que oscilan entre el constructivismo y el realismo, según sea la interpretación que se haga de la relación entre los conceptos de verdad y de corrección moral con aquel otro de aceptabilidad racional. La interpretación realista o no reduccionista propuesta, entre otros, por Cristina Lafont ha abierto un fructífero debate que no sólo se limita a la teoría consensual de la verdad, sino que se extiende a la ética discursiva. Este trabajo se propone analizar las consecuencias de dicha interpretación para la teoría del discurso jurídico.

Palabras clave: Constructivismo, realismo, objetividad, discurso jurídico, Aarnio, Alexy.

\section{INTRODUCCIÓN.}

Sostener a estas alturas que la moderna teoría de la argumentación jurídica ha derivado en una teoría discursiva de la argumentación jurídica o, si se prefiere, en una teoría del discurso jurídico, no requiere una especial justificación, si se considera el enorme impacto que la teoría del discurso desarrollada por Karl-Otto Apel y Jürgen Habermas, ha tenido en autores como Aulis Aarnio, Aleksander Peczenik y, muy especialmente, Robert Alexy ${ }^{1}$. Por otra parte, la repercusión que los desarrollos producidos en el ámbito jurídico han tenido en la teoría habermasiana indican que ésta ha sido, y sigue siendo hoy día, una relación fructífera en ambas direcciones ${ }^{2}$. De

\footnotetext{
${ }^{1}$ Neumann, U. Juristische Argumentationslehre, Darmstadt, Wissenschaftliche Buchgesellschaft, 1986, p. 2. Por otra parte, es de cobra conocida la influencia que en el desarrollo de la teoría de la argumentación han ejercido autores como Viehweg, Perelman, Toulmin o Recaséns; en este sentido, véanse, además de la obra de Neumann, las de Manuel Atienza (Atienza, M. Las razones del derecho. Teorías de la argumentación jurídica, Madrid, Centro de Estudios Constitucionales, 1997) y Evelin Feteris (Feteris, E. Fundamentals of Legal Argumentation. A Survey of Theories on the Justification of Judicial Decisions, Dordrecht/Boston/London, Kluwer, 1999).

${ }^{2}$ Como el propio Habermas reconoce, fue la Teoría de la argumentación jurídica de Alexy lo que le llevó a una ampliación de la teoría del discurso, planteada en origen para la moralidad, al ámbito del derecho y del Estado constitucional ("Replay to Symposium participants, Benjamin N. Cardozo School of Law", Revista de Direitos Fundamentais \& Democracia, Curitiba, v. 25, n. 3, p. 133-159, set./dez. 2020
} 
hecho, todavía está por ver las implicaciones para la teoría del derecho de uno de los más importantes debates desarrollados en el marco de la teoría del discurso en tiempos recientes. Me refiero a la discusión mantenida por Habermas con Albretch Wellmer y, sobre todo, con Cristina Lafont ${ }^{3}$, que le han forzado a abandonar su teoría consensualista de la verdad y mantienen en jaque la actual concepción constructivista de la ética discursiva.

La tesis central de la interpretación realista o no reduccionista anticipada por Wellmer y ampliamente desarrollada por Lafont consiste en la negación del carácter constitutivo de la relación entre las nociones de aceptabilidadracional y verdad (o corrección moral) o, en un sentido más general, entre justificación y validez. La verdad o la corrección moral de las proposiciones empíricas o normativas no dependen de que éstas sean aceptadas por todos, ni siquiera en un discurso realizado bajo condiciones ideales ${ }^{4}$. Dicho de otro modo, el consenso alcanzado discursivamente no es condición necesaria ni suficiente para la verdad o corrección de las creencias contenidas en esas proposiciones.

En sus trabajos más recientes Lafont ${ }^{5}$ se ha aproximado al terreno de la filosofía jurídica, si bien su interés se ha centrado principalmente en la teoría discursiva de la democracia. En este escrito pretendo dirigir la atención al discurso de aplicación del derecho (en adelante discurso jurídico), analizando las consecuencias que para el mismo tiene el "giro realista" en la teoría del discurso. En mi opinión, el concepto de corrección jurídica debe someterse a la misma estrategia seguida por Lafont para explicar los conceptos de verdad y corrección moral (justicia). La interpretación realista o no reduccionista del discurso jurídico que aquí se propone refuerza la intuición de que es la pretensión de corrección (que denominaré como pretensión de corrección jurídica), y no el consenso o el procedimiento, la noción central de toda aquella teoría

Cardozo Law Review 17(5), 1996, pp. 1477-1558, aquí p. 1529). Igualmente influyente en el posterior desarrollo de la teoría del discurso ha sido la distinción introducida por Klaus Günther entre discursos de justificación y discursos de aplicación (vid. Günther, K., Der Sinn für Angemessenheit. Anwendungsdiskurse in Moral und Recht, Frankfurt a. M., Suhrkamp, 1988).

3 Una buena exposición de este debate puede verse en el libro de Pere Fabra, Habermas: Lenguaje, Razón y Verdad, Barcelona, Marcial Pons, 2008, cap. IX.

4 Sobre las reglas que definen el discurso racional, vid. Alexy, R. Teoría de la argumentación jurídica. La teoría del discurso racional como teoría de la fundamentación jurídica, trad. M. Atienza e I. Espejo, CEC, Madrid, 1997, pp. 283 y ss.; Habermas, J. "Ética del discurso. Notas sobre un programa de fundamentación", en Id. Conciencia moral y acción comunicativa, trad. Ramón García Cotarelo, Barcelon, Península, 1985, pp. 57-134.

5 "Law, Normativity and Legitimacy. Can Moral Constructivism be Fruitful for Legal Theory?", en Bertea, S. / Pavlakos, G. (eds.), New Essays on the Normativity of Law, Oxford / Portland, Hart, 2011, pp. 229-245; "Correctness and Legitimacy in the Discourse Theory of Law", en Klatt, M. (ed.), Institutionalized Reason. The Jurisprudence of Robert Alexy, Oxford, OUP, 2012, 291-306.

Revista de Direitos Fundamentais \& Democracia, Curitiba, v. 25, n. 3, p. 133-159, set./dez. 2020 
de la argumentación jurídica que comparta las pretensiones congnoscitivistas de la ética discursiva.

El trabajo se divide en dos grandes apartados: el primero se centrará en la crítica a la interpretación constructivista de la teoría del discurso; en el segundo se perfilará la naturaleza de las pretensiones de validez en el discurso jurídico.

\section{UNA CRÍTICA CONSTRUCTIVA DEL CONSTRUCTIVISMO: LA INTERPRETACIÓN REALISTA DE LA TEORÍA DEL DISCURSO.}

\subsection{La teoría consensual de la verdad.}

Aunque Habermas ha rechazado explícitamente su teoría consensual de la verdad $^{6}$, el debate que precede a esa renuncia sienta las bases de la discusión todavía abierta- acerca de una posible interpretación realista de la ética discursiva.

Muy resumidamente, las bases de la teoría consensual de la verdad son las siguientes. Desde una perspectiva pragmática, la verdad es definida como una pretensión de validez que formulamos al afirmar que algo es el caso. En consecuencia, una enunciado es verdadero cuando la pretensión de validez que expresamos con dicho enunciado está justificada; y una pretensión está justificada si en un proceso argumentativo desarrollado en condiciones de racionalidad resulta aceptada. Por tanto:

\footnotetext{
"[l]a condición para la verdad de los enunciados es el potencial asentimiento de todos los demás"; o sea, "[l]a verdad de una proposición significa la promesa de alcanzar un consenso racional sobre lo dicho"7.
}

Así, de acuerdo con la teoría consensual, la verdad tiene un carácter epistémico: " $p$ es verdadero" significa " $p$ está justificado (es susceptible de aceptabilidad racional)".

La tesis expuesta es difícilmente compatible con la intuición realista, también sostenida por Habermas, de que un enunciado es verdadero "si y sólo si refleja un estado de cosas real o un hecho"8. Si esta intuición es correcta, entonces un enunciado no puede ser verdadero simplemente porque es tenido por válido, esto es, justificado

\footnotetext{
6 Vid. Habermas, J. "Verdad y Justificación. El giro prágmático de Rorty", en Id. Verdad y Justificación, trad. Pere Fabra y Luis Díez, Madrid, Trotta, pp. 223-259

${ }^{7}$ Habermas, J. "Teorías de la verdad", en Id. Teoría de la acción comunicativa: complementos y estudios previos, trad. Manuel jiménez Redondo, Madrid, Cátedra, 1997 ( $3^{\mathrm{a}}$ ed.), pp. 113-158; aquí p. 121.

8/dem., p. 114.

Revista de Direitos Fundamentais \& Democracia, Curitiba, v. 25, n. 3, p. 133-159, set./dez. 2020
} 
discursivamente. El núcleo de las críticas a la teoría consensual de la verdad es la distancia lógica entre los conceptos de verdad y justificación (o aceptabilidad racional). Estas críticas se pueden agrupar en tres argumentos:

(i) La incapacidad de las condiciones de racionalidad del discurso para garantizar la verdad o corrección de sus resultados. Como ha mostrado Wellmer ${ }^{9}$, la verdad no se sigue necesariamente de las condiciones formales -simetría e inclusiónde la discusión, sino de la calidad (contenido) de las razones; y, a la inversa, esta última no depende de aquellas. Las razones que justifican " $p$ " en el momento $t_{1}$ pueden ser insuficientes o incluso incorrectas en $t_{2}$, pero esto no significa necesariamente que el consenso alcanzado en $t_{1}$ fue obtenido en condiciones de coacción o exclusión.

La identificación de la verdad con la aceptabilidad racional haría necesario añadir algún tipo de capacidad de juicio de los participantes (Urteilskraft) a las condiciones del discurso para poder garantizar la corrección material de sus resultados ${ }^{10}$. Naturalmente, esto supondría una modificación sustancial de las condiciones de racionalidad del discurso, que plantearía el siguiente problema: si dicha capacidad de juicio es un presupuesto de la teoría, resulta manifiestamente falso en algunos casos; si dicha capacidad es una exigencia, aquellos que no la acrediten deben ser excluidos de la discusión ${ }^{11}$.

(ii) La independencia conceptual entre verdad y justificación. La prueba de que los conceptos de verdad y justificación no son interdefinibles es la irreductibilidad de las condiciones del conocimiento. Cuando afirmo que " $p$ ", no sólo formulo la pretensión de que " $p$ " es verdad, sino también que tengo razones para creer que " $p$ ". El hecho de que " $p$ " podría ser verdad aunque yo no tuviera razones para creerlo, o las razones que tenía para hacerlo fueran equivocadas, o de que pudiera no ser verdadero a pesar de que yo tuviera buenas razones para creerlo así, muestran la

9 Wellmer, A. Étca y diálogo. Elementos del juicio moral en Kant y en la ética del discurso, trad. Fabio Morales, Barcelona, Anthropos, 1994, pp. 95 y ss.

10 Este presupuesto es explícitamente reconocido por Alexy: "Desde luego, hay que admitir que la observancia de las reglas del discurso no garantiza todavía la bondad de los argumentos. Esto conduce a una premisa esencial para la teoría del discurso y que hasta ahora, por lo general, ha sido demasiado poco destacada. La teoría del discurso presupone que los participantes del discurso, es decir, las personas tal como realmente existen, están básicamente en condiciones de distinguir las buenas de las malas razones. Parte, pues, de una básicamente existente facultad de juicio de los participantes" (Alexy, R. "Una concepción teórico-discursiva de la razón práctica”, en Id. El concepto y la validez del derecho, trad. Jorge M. Seña, Barcelona, Gedisa, pp. 131-158, cita en p. 139).

11 En un sentido similar, Atienza ha sostenido que "si [la capacidad de juicio de los participantes] se interpreta como una afirmación empírica, es sin duda falso; y si se interpreta de otra forma, corre el riesgo de convertirse en una ficción que probablemente no pueda cumplir más que una función ideológica: la de ocultar que un discurso racional no siempre es posible" (Atienza, M. Las razones del derecho, op. cit., p. 209).

Revista de Direitos Fundamentais \& Democracia, Curitiba, v. 25, n. 3, p. 133-159, set./dez. 2020 
independencia conceptual entre verdad y justificación ${ }^{12}$.

En esta misma línea, Wellmer apunta que la idea de verdad incorpora un "plus (Überschluß) inevitable" respecto a aquella de una pretensión de validez (discursivamente) justificada, puesto que ninguna justificación real puede excluir la posibilidad de que experiencias futuras modifiquen el resultado del discurso. En opinión de Wellmer, la verdad es una idea regulativa que no debe entenderse como la expresión de la aspiración a un saber futuro, absoluto y definitivo -algo así como una resolución definitiva de nuestras pretensiones de verdad en un "consenso final"- sino en un sentido falibilista, para el que "todo conocimiento, todo consenso racional (...) debe ser considerado con reservas" 13 .

Esta distinción se advierte igualmente en nuestro uso de ambas nociones. En primer lugar, usamos la oposición verdadero/falso de un modo binario (principio del tercero excluido), en contraste con el carácter gradual de la justificación; y, en segundo lugar, atribuimos a la verdad un carácter permanente (es decir, al hecho de que "ser verdadero" es una propiedad que los enunciados no pueden perder), del que carece la justificación. Así, la noción de verdad presenta una validez incondicional que no atribuimos a la aceptabilidad racional ${ }^{14}$. De este modo, podemos decir que, conforme a las condiciones epistémicas disponibles en un momento dado, " $p$ " estaba justificado, pero que en las circunstancias presentes ya no lo está. En cambio, no podemos decir que " $p$ " era verdad, pero ya no lo es; decimos que " $p$ " era considerado (erróneamente) como verdadero, pero, en realidad, no lo era. Estas propiedades -el principio del tercero excluido y el carácter permanente- implican la "unidad de respuesta correcta" para las cuestiones empíricas.

(iii) Problemas relativos a la idealización. Podría decirse todavía que las dos objeciones anteriores no captan la idea de la concepción epistémica de la verdad entendida como "aceptabilidad racional bajo condiciones ideales". Para que la noción de aceptabilidad racional bajo condiciones ideales reflejara la validez incondicional que atribuimos a la verdad, debería ser entendida como un consenso definitivo no sujeto a revisión que no sólo debe mostrar que ha sido obtenido bajo condiciones racionales (simetría e inclusividad), sino también que todo argumento posible, presente o futuro,

12 Lafont, C. The Linguistic Turn in Hermeneutic Philosophy, trans. José Medina, Cambridge (Mass.), MIT Press, 1999, pp. 291-2.

13 Wellmer, A. "Was ist eine pragmatische Bedeutungstheorie? Variationen über den Satz 'Wir verstehen eine Sprechakt, wenn wir wissen, was inn akzeptabel macht"', in Honnet, A. et al. (Hrsg.) Zwischenbetragtungen. Im Proze $\beta$ der Aufklärung. Jürgen Habermas zum 60. Geburstag. Frankfurt an Main, Surkamp, 1989, pp. 318-370; aquí p. 340.

${ }^{14}$ Lafont, C. The Linguistic Turn in Hermeneutic Philosophy, op. cit., p. 293.

Revista de Direitos Fundamentais \& Democracia, Curitiba, v. 25, n. 3, p. 133-159, set./dez. 2020 
ha sido tomado en consideración.

Esta idea, sin embargo, es problemática por dos razones. En primer lugar, se enfrenta a una objeción que puede oponerse frente a cualquier concepción consensual de la verdad, relativa a la idealización de las condiciones epistémicas bajo las que se produce el consenso y que conduce al siguiente dilema, tal y como es formulado por Habermas en su retractación:

\begin{abstract}
"Con independencia de cómo se sobrevaloren, idealizándolas, las condiciones epistémicas, o bien satisfacen el carácter incondicionado de las pretensiones de verdad mediante exigencias que imposibilitan todo contacto con las prácticas de justificación que nos son conocidas; o bien mantienen el vínculo con un práctica que conocemos, pero al precio de que la aceptabilidad racional, incluso bajo estas condiciones ideales, no deja entonces de excluir el error, es decir, no suponen ninguna propiedad que los enunciados no puedan perder"15.
\end{abstract}

Una cuestión esencial en este punto estriba en qué escenario hipotético describen las "condiciones ideales" bajo las que tiene lugar la aceptabilidad racional. Si las condiciones ideales son concebidas de modo que contienen la idea de un consenso final definitivo, entonces -en palabras de Wellmer- van más allá de toda experiencia posible ${ }^{16}$, superan los límites de lo humanamente inteligible. Si, por el contrario, las condiciones ideales son definidas como presupuestos contrafácticos de la comunicación o cualquier otra práctica de justificación (y mantienen, por tanto, el vínculo con una práctica que conocemos), entonces, no pueden garantizar por sí solas la corrección absoluta de los resultados de dicha práctica.

El segundo problema en relación a la idealización de las condiciones de racionalidad es que las implicaciones de dicha idealización no son compatibles con una explicación teórico-discursiva de la racionalidad. Como señala Lafont, si la pretensión de aceptabilidad racional de nuestros argumentos y creencias implica la idea de un consenso definitivo, es decir, un consenso inatacable e inalterable por cualquier argumento futuro, dicha pretensión no tiene nada que ver con el proceso argumentativo en el que las razones se muestran convincentes para todos, esto es, no tiene nada que ver con la concepción discursiva de aceptabilidad racional, sino con el contenido de

15 Habermas, J. "Verdad y Justificación. El giro prágmático de Rorty", op. cit., p. 247.

16 Wellmer, A. Étca y diálogo, op. cit., p. 103. Un ejemplo de idealización que se sitúa fuera de estos márgenes de lo concebible es la definición de Alexy, para quien un discurso ideal sería aquel desarrollado en "condiciones ilimitadas de tiempo y participación, ausencia total de coacción que impida la consecución de una completa claridad lingüístico-conceptual, con una completa información empírica, capacidad y disposición absolutas para el intercambio de roles y una ausencia total de prejuicios" (Alexy, R. "Probleme der Diskurstheorie", en Id. Recht, Vernunft, Diskurs, Frankfurt am Main, Suhrkamp, 1995, pp. 109-126, cita en p. 113). Para un análisis en detalle de la concepción alexiana del discurso, vid. Bäcker, C. Begründen und Entscheiden. Kritik und Rekonstruktion der Alexyschen Diskurstheorie des Rechts, Baden-Baden, Nomos, 2008, especialmente pp. 117 y ss.

Revista de Direitos Fundamentais \& Democracia, Curitiba, v. 25, n. 3, p. 133-159, set./dez. 2020 
dichas razones:

\begin{abstract}
"En tal caso, la racionalidad del proceso de argumentación no depende de la coacción no coactiva del mejor argumento en una situación ideal de habla. Más bien, depende de que se tengan, de hecho, los mejores argumentos (...) Si lo que es aceptable racionalmente bajo condiciones ideales posee también la validez absoluta que le atribuimos a la verdad, nuestro compromiso con la racionalidad no es un compromiso con la falibilidad o la racionalidad discursiva. Por el contrario, es un compromiso con la incorregibilidad"17.
\end{abstract}

En definitiva, una afirmación " $p$ " es verdadera si y sólo si reproduce un estado de cosas real o un hecho. La verdad depende únicamente de lo que es el caso, de cómo es el mundo objetivo. Por esta razón, la verdad conserva su validez incondicional respecto de cualquier criterio epistémico de aceptabilidad racional $\mathrm{y}$, viceversa, todo criterio epistémico depende de una circunstancia no epistémica. Esta dependencia de circunstancias no epistémicas -que algo que sea el caso- permite explicar la potencial falibilidad de cualquier criterio epistémico, incluido el discurso racional.

Aunque en la interpretación realista de la teoría de la verdad, la verdad (validez) trasciende la justificación (aceptabilidad racional), entre ambas persiste una relación interna: la aceptabilidad racional aparece como condición necesaria, pero no suficiente de nuestras pretensiones de saber. Por lo dicho hasta ahora, esta relación interna no deriva de una exigencia semántica, es decir, no forma parte del significado de verdad, sino de una exigencia pragmática que afecta al uso del predicado verdadero en relación con cualquier creencia ${ }^{18}$. Al no haber otro acceso a la verdad que no sea a través del lenguaje, cada vez que afirmamos " $p$ " como un saber, debemos estar en condiciones de justificarlo. Esta justificación está sujeta, obviamente, a los criterios epistémicos de aceptabilidad racional, pero no importa cuán convincentes podamos ser en nuestras prácticas justificativas; siempre, incluso bajo condiciones ideales, cabe la posibilidad de que estemos equivocados.

\title{
2.2. Corrección moral y teoría del discurso.
}

Como ha mostrado la evolución de la propia teoría del discurso, el contexto práctico es mucho más complejo que el teórico, en cuanto que no hay un único criterio de corrección para los juicios de deber (hablamos así de corrección moral, política, jurídica o religiosa), como lo hay para los enunciado empíricos. No obstante, las

\footnotetext{
17 Lafont, C. The Linguistic Turn in Hermeneutic Philosophy, op. cit., p. 295-296.

$18 / d e m .$, p. 310.

Revista de Direitos Fundamentais \& Democracia, Curitiba, v. 25, n. 3, p. 133-159, set./dez. 2020
} 
pretensiones de validez formuladas cuando juzgamos nuestras acciones o cuando afirmamos que una conducta debe ser establecida como pauta general mediante una norma son igualmente susceptibles de ser problematizadas en un discurso racional. Aquí nos limitaremos a una de esas perspectivas: la corrección moral o justicia.

Uno de los postulados centrales de la teoría del discurso es el carácter cognoscitivo de las pretensiones de validez moral, o sea, que del resultado de un discurso desarrollado en condiciones de racionalidad no sólo se puede predicar su imparcialidad (fair), sino su corrección. Al igual que en los discursos teóricos, las condiciones formales de la argumentación -simetría e inclusión- son condición necesaria para la aceptabilidad racional de nuestras pretensiones de validez en los discursos morales, pero, ¿son también condición suficiente para su validez? Aquí es donde difieren la interpretación realista o no reduccionista (i) y la interpretación constructivista (ii).

(i) Conforme a la interpretación realista, las razones para mantener la separación conceptual entre validez (corrección) y justificación (aceptabilidad racional) valen también para el discurso práctico, en tanto que las condiciones necesarias y suficientes de la corrección moral no dependen de circunstancias epistémicas, lo que significa que atribuimos a la justicia, como a la verdad, una validez incondicional. Como ya sabemos, las condiciones necesarias y suficientes de validez de un enunciado descriptivo son que éste exprese un estado de cosas o un hecho; en otras palabras, un enunciado descriptivo " $p$ " es verdadero si $p$ es el caso. Es la presuposición no epistémica de uno y el mismo mundo objetivo para todos lo que permite hablar de validez incondicional de las pretensiones de verdad. Lafont sostiene que podemos encontrar una presuposición equivalente (no epistémica) para el ámbito moral en la noción de "intereses generalizables". De hecho, esta noción estaría ya contenida en el principio de universalización (U), según el cual una norma está moralmente justificada cuando:

\footnotetext{
"todos puede aceptar libremente las consecuencias y efectos colaterales que se producirán previsiblemente del cumplimiento general de una norma polémica para la satisfacción de los intereses de cada uno"19.
}

En la formulación de este principio deben diferenciarse dos elementos: por un

\footnotetext{
19 Habermas, J. "Ética del discurso. Notas sobre un programa de fundamentación”, en Id. Conciencia moral y acción comunicativa, trad. Ramón García Cotarelo, Barcelon, Península, 1985, pp. 57-134, cita en p. 116.

Revista de Direitos Fundamentais \& Democracia, Curitiba, v. 25, n. 3, p. 133-159, set./dez. 2020
} 
lado, el principio discursivo (D), que especifica las condiciones generales de aceptabilidad racional ("todos puedan aceptar libremente" recoge las condiciones fundamentales de inclusión y simetría en el discurso); y, por otro lado, una definición del punto de vista moral (a saber: una norma es moralmente correcta si "satisface losinteresesdecada uno"). (D) establece cuándo una norma puede sertenida por moralmente correcta (lo cual no quiere decir que lo sea definitivamente) y es, por tanto, un criterio de justificación, Por otra parte, y en tanto que definición, el segundo elemento establece las condiciones necesarias y suficientes para que una norma sea (y no sólo se tenga por) moralmente correcta.

El objeto de todo discurso es, precisamente, dilucidar si una proposición o una norma satisfacen las condiciones necesarias y suficientes de validez; de esto tratan nuestras argumentaciones: de si es el caso que " $p$ " (si " $p$ " es verdadero) o de si una norma $\mathrm{N}_{1}$ protege intereses generalizables (si $\mathrm{N}_{1}$ es justa). Pero con ello ya se están asumiendo los presupuestos de carácter formal, que el mundo es uno y el mismo para todos y la existencia de intereses generalizables o universalizables. Es preciso insistir en su carácter formal, porque al asumirlos no dice cómo sea el mundo, ni cuáles sean esos intereses generalizables, sino únicamente que la verdad de las descripciones del mundo, así como la corrección moral de las normas dependen de circunstancias objetivas independientes de las condiciones epistémicas dadas en un discurso. Ahora bien, sólo a través de un discurso estaremos en condiciones de afirmar que una norma satisface o no las condiciones de validez.

En definitiva, según la interpretación realista, la corrección moral no puede reducirse a la aceptabilidad racional. Ésta es un criterio para sostener justificadamente la justa de una norma ( $\mathrm{y}$, como tal criterio, falible), pero una norma sólo es justa cuando dehecho protege intereses generalizables".

(ii) Habermas, en cambio, mantiene el carácter constitutivo del discurso moral. Esta interpretación constructivista (y reduccionista) de la ética discursiva sostiene que la aceptabilidad racional no es sólo un criterio de justificación que permite afirmar la corrección moral de una norma, sino que es la definición de corrección moral. En él ámbito de la moralidad, la validez no trasciende la justificación, como sí ocurre en los discursos teóricos: los resultados de los discursos morales desarrollados en condiciones ideales no sólo deben ser considerados justificados, sino también correctos. La existencia de un mundo objetivo, independiente de nuestras percepciones y descripciones, permite una "explicación ontológica" de la pretensión de 
verdad y su diferenciación de la pretensión de justificación de los saberes teóricos, en cambio, la validez moral -dice Habermas- carece de un equivalente ontológico:

\footnotetext{
"No entendemos la validez de un enunciado normativo en el sentido de la existencia de un estado de cosas, sino por la capacidad de ser digna de reconocimiento que posee la norma correspondiente"20.
}

La validez en el contexto moral no puede ser explicada recurriendo a una referencia externa, a un mundo objetivo, sino a un proceso progresivo de inclusión a través de la adopción de las perspectivas de los otros; no hay un mundo social distinto de nuestras prácticas y nuestras propias preferencias. Nada hay, pues, en el significado de la validez moral que pueda llevarnos más allá de la aceptabilidad racional en condiciones ideales, lo que confiere a los discursos morales carácter constitutivo:

\begin{abstract}
"Un acuerdo sobre normas o acciones que haya sido alcanzado discursivamente bajo condiciones ideales posee algo más que una mera fuerza autorizante: garantiza la corrección de los juicios morales"21.
\end{abstract}

\title{
2.3. Falibilismo y objetividad en los discursos morales.
}

La distinción conceptual entre la validez y la justificación discursiva de las normas morales en que se fundamenta la interpretación realista del discurso ha mostrado una mayor virtualidad explicativa que su alternativa. Así, permite distinguir la aceptabilidadracional en un proceso discursivo, del mero compromiso de intereses resultante de un procedimiento de negociación imparcial, desarrollado igualmente en condiciones de simetría e inclusión, al que no atribuimos un carácter cognoscitivo, sino decisionista22; pero, sobre todo $-\mathrm{y}$ este es el punto en el que me centraré aquíproporciona una mejor explicación del falibilismo de nuestras prácticas de justificación (presupuesto inherente de la racionalidad comunicativa.

La concepción del error es un elemento central para dar cuenta de la objetividad y la naturaleza cognoscitiva de una teoría. Aunque la cuestión es

20 Habermas, J. "Corrección normativa versus verdad. El sentido de la validez deontológica de los juicios y normas morales", en Id. Verdad y Justificación, trad. Pere Fabra y Luis Díez, Madrid, Trotta, pp. 261-303, cita en p. 284.

21 Habermas, J. "Corrección normativa versus verdad", op. cit., p. 285.

22 Lafont, C. "Procedural Justice? Implications of the Rawls-Habermas Debate for Discourse Ethics", Philosophy and Social Criticism 29 (2003), pp. 167-185; Id. "Moral Objectivity and Reasonable Agreement: Can Realism Be Reconciled with Kantian Constructivism?", Ratio luris 17 (2004), pp. 2751.

Revista de Direitos Fundamentais \& Democracia, Curitiba, v. 25, n. 3, p. 133-159, set./dez. 2020 
enormemente compleja, para poder hablar de objetividad en un contexto cualquiera es necesario, al menos, concebir un "espacio lógico" entre nuestras percepciones y juicios acerca de las cosas y cómo éstas son de acuerdo a un estándar ${ }^{23}$. Pues bien, no es sólo que en la interpretación realista este espacio lógico es más amplio (hasta el punto en que cabría admitir, siquiera teóricamente, el error colectivo), sino que la interpretación constructivista tiende a estrecharlo a medida en que los discursos se aproximen a las condiciones ideales de racionalidad.

Hay, al menos, dos argumentos que hablan a favor de la interpretación realista o no reduccionista del discurso. En primer lugar, al equiparar aceptabilidad racional con corrección moral, como defiende la versión constructivista, una hipotética revisión futura de los resultados de un discurso desarrollado en condiciones ideales de racionalidad resultaría tan innecesaria como inconcebible. En este sentido, un concepto puramente procedimental de la corrección moral comprometería la propia concepción teórico-discursiva de la racionalidad. Como se ha advertido más arriba, si a la aceptabilidad racional bajo condiciones ideales le atribuimos validez incondicional (que es lo que ocurre cuando definimos la corrección moral en términos de aceptabilidad racional), la pretensión de validez que plantean los hablantes en un discurso debe, necesariamente, implicar la idea de un consenso final, definitivo e irrevisable, esto es, inmune a todo argumento futuro. En otras palabras, la pretensión de corrección implica igualmente una pretensión de infalibilidad. Con esto ya se ha perdido la conexión con la racionalidad discursiva. En tanto que las condiciones procedimentales (formales) de simetría e inclusión no son suficientes para garantizar la corrección objetiva de los resultadosdel discurso, la identificación de la corrección con la aceptabilidad racional en condiciones ideales exige presuponer una capacidad de juicio esclarecida -de hecho, infalible- que garantice que únicamente las respuestas correctas van a resultar aceptadas por los hablantes en un discurso ideal. De existir una capacidad tal, los discursos serían innecesarios. Por otro lado, con una asunción de este tipo, la idea de racionalidad estaría asociada a la corrección sustantiva más que al procedimiento argumentativo.

Esta idea se ve confirmada en el segundo de los argumentos a favor de una interpretación realista del discurso moral, que se refiere a la explicación y naturaleza de los errores en la teoría discursiva. El problema del error se plantea bien cuando

${ }^{23}$ Stavropoulos, N. "Objectivity", en Golding, M. P. / Edmundson, W. A. (eds), The Blackwell Guide to the 
sospechamos que una norma que tenemospor justificada puede ser injusta (por ejemplo, en su momento, la esclavitud o la desigualdad entre sexos), bien cuando dos normas incompatibles aspiran a ser justificadas y, con ello, ser tenidas por justas.

En relación con el segundo caso, la explicación del error o delo que aparentemente constituye un error podría consistir en la renuncia a la premisa de la unidad de respuesta correcta en nuestros juicios morales. Ello significaría que el campo de lo discursivamente posible es, o puede ser, mayor a uno; esto es, admitiendo que dos normas, $\mathrm{N}_{1}$ y $\mathrm{N}_{2}$, que califican una misma acción $X$ como permitida y obligatoria, respectivamente, son ambas moralmente correctas. Esta forma de entender la corrección resulta problemática cuando menos ${ }^{24}$, especialmente desde el punto de vista del participante en los discursos morales, en los que se discuten intereses universalizables. En realidad, esta ampliación de la extensión de lo moralmente correcto no constituye una explicación de la falibilidad, sino, más bien, de la incapacidad de las condiciones formales de los discursos para generar un único resultado.

Si no se quiere pagar el alto precio de renunciar a la premisa de la unidad de respuesta correcta, la única explicación posible del error moral desde una interpretación constructivista pasa necesariamente por ser una explicación de tipo procedimental, o sea, poniendo de manifiesto problemas de asimetría o de exclusión en el desarrollo de los discursos ${ }^{25}$. Dicho en otras palabras, que el acuerdo no fue obtenido en plenas condiciones de racionalidad. Ahora bien, si toda explicación del

24 En esta misma línea, Juan Carlos Bayón ha sostenido que "si no hay ningún sentido en el que quepa hablar de "racionalidad práctica" más allá del seguimiento de las reglas del discurso, quien repara en que la posición por él defendida es sólo "discursivamente posible" -y entonces, por definición, tan "discursivamente posible" como la contraria- no puede "dar razón" de por qué mantiene esa posición y no la contraria, ni asociar una "pretensión de objetividad" o de "corrección" a la posición mantenida (a no ser en un sentido francamente singular de "objetividad" o "corrección" que no excluya el que lo sea igualmente otra posición incompatible con ella)" (Bayón Mohino, J. C. La normatividad del derecho: deber jurídico y razones para la acción, Madrid, C.E.C., 1991, p. 228, nota 305). De manera similar, Peter Gril ha señalado que si lo discursivamente posible es mayor a uno, los participantes carecen de razones para renunciar a sus convicciones correctas a favor de las convicciones correctas de otros participantes (Gril, P. Die Möglichkeit praktischer Erkenntnis aus Sicht der Diskurstheorie. Eine Untersuchung zu Jürgen Habermas und Robert Alexy, Berlin, Duncker \& Humblot, 1998, p. 157).

25 Este parece ser el planteamiento de Habermas: "Cuando hay afectados excluidos y éstos no pueden participar en la discusión, cuando se reprimen temas o se suprimen contribuciones relevantes, cuando no se articulan sinceramente o no se formulan de un modo convincente los intereses determinantes o cuando no se respeta a los otros en su otredad, debemos contar entonces con que no se dan -0 ni tan sólo se expresan- las tomas de posición racionalmente motivadas. Este falibilismo es totalmente compatible con el carácter definitivo que tiene para nosotros un acuerdo respecto al cual suponemos -acertadamente o no- que ha sido logrado bajo condiciones de justificación suficientemente ideales" (Habermas, J. "Corrección normativa versus verdad”, op. cit., p. 286).

Revista de Direitos Fundamentais \& Democracia, Curitiba, v. 25, n. 3, p. 133-159, set./dez. 2020 
error moral reside en los déficits de los discursos reales (más o menos próximos a la realización de las condiciones ideales que forman parte del significado de "corrección moral"), entonces, como se ha advertido más arriba, se estaría presuponiendo la infalibilidad de nuestra capacidad de juicio en condiciones ideales.

Pero, hay algo más aparte de sobrecargar la pretensión de corrección con un sentido de infalibilidad. Para la interpretación constructivista, en tanto que la corrección moral depende exclusivamente de la aceptabilidad racional, la explicación del error moral es necesariamente procedimental y, por definición, no puede hacer referencia a circunstancias objetivas que trasciendan la situación epistémica dada en el discurso ideal. Esta limitación no estará presente en la interpretación realista del discurso moral, que presupone el carácter objetivo de los intereses irrenunciables o generalizables. En este sentido, Lafont menciona tres circunstancias que no sólo hacen posible, sino que hacen necesaria, una explicación no procedimental del error moral. En primer lugar, en la medida en que dependen "menos de "nuestro hacer" que de nuestra condición humana (...) parece que reconocemos una (posible) discrepancia entre nuestros intereses irrenunciables y la evidencia que podamos tener en un momento determinado"26. Segundo, porque "incluso bajo el supuesto de que el acceso a nuestros intereses irrenunciables nos resultara completamente transparente, ello no constituiría garantía alguna relativa al conocimiento de los intereses irrenunciables de los demás", conocimiento del que depende "la condición de estar "igualmente en interés de todos y cada uno" requerida por la corrección moral" 27 . Y, por último, "incluso admitiendo que nunca pudiéramos equivocarnos con relación a nuestros intereses irrenunciables, eso no podría garantizar un conocimiento infalible relativo a las consecuencias objetivas que una norma tendría a largo plazo y en circunstancias cambiantes (es decir, normalmente impredecibles) para todos los afectados" 28 . Los tres

${ }^{26}$ Lafont refuerza esta idea con el siguiente argumento: "Si seguimos buscando aquellas normas que de hecho están igualmente en interés de todos, a pesar de las dificultades para superar nuestros desacuerdos epistémicos, sólo puede ser porque, dada cualquier sospecha relativa a si una norma es justa, la opción de cambiar los intereses afectados en lugar de la norma no es realmente viable" (Lafont, C. "Realismo y constructivismo en la Teoría moral kantiana: el ejemplo de la ética discursiva", Isegoría 27 (2002), pp. 115-129, citas en p. 129; vid. también Lafont, C. "How cognitivist is Discourse Ethics?", en Niquet, M. Et al. (Hrsg.), Diskursethik. Grundlegungen und Andwendungen, Wurzburg, Könighausen \& Neumann, 2001, pp. 135-144, cita en p.144, nota 10, y Lafont, C. The Linguistic Turn in Hermeneutic Philosophy, op. cit., p. 336).

27 Idem.

${ }^{28}$ /dem. Esta posibilidad también ha sido considerada por Habermas, que se refiere a ella como "otro tipo de falibilismo", en contraposición al falibilismo de tipo procedimental, fundado en un insuficiente cumplimiento de las reglas del discurso. Habermas admite que "las normas reconocidas como válidas, aun en el caso de estar bien fundamentadas, pueden ser complementadas mediante discursos de aplicación", en tanto que "determinadas circunstancias no previstas o nuevos hechos Revista de Direitos Fundamentais \& Democracia, Curitiba, v. 25, n. 3, p. 133-159, set./dez. 2020 
supuestos comparten el mismo trasfondo realista al presuponer la existencia de unos intereses generalizables que dependen más de circunstancias objetivas (la condición humana) que de la percepción que de ellos podamos tener. La percepción equivocada de estar circunstancias puede llevarnos a tener por justificada una norma que de hecho no protege intereses generalizables.

En definitiva, únicamente una interpretación realista del discurso moral, que distingue conceptualmente entre aceptabilidad racional y corrección moral, está en condiciones de proporcionar una explicación comprehensiva del falibilismo en los discursos morales. En tanto que sólo en un discurso racional puede una razón sustantiva ser considerada como razón a favor de la validez de una norma, la aceptabilidad racional es condición necesaria de la justificación, sin embargo, en tanto que la corrección moral de las normas depende de circunstancias objetivas que exceden las condiciones epistémicas dadas en un discurso ideal, esto es, depende de que la norma dehecho vaya en interés de todos, no es condición suficiente para la corrección moral.

\section{CORRECCIÓN Y JUSTIFICACIÓN EN EL DISCURSO JURÍDICO.}

Uno de los objetivos de este trabajo es dilucidar la naturaleza de la pretensión de validez formulada en el discurso jurídico ${ }^{29}$ (corrección jurídica), o más concretamente, si dicha pretensión comparte con las pretensiones de validez y corrección moral el carácter incondicional. Es preciso advertir desde un principio que ésta no es una cuestión pacífica ni siquiera entre los teóricos de la argumentación jurídica que se sitúan en la órbita de la teoría discursiva.

\subsection{Las pretensiones de validez de los discursos jurídicos.}

Hasta ahora he presentado una interpretación realista de la teoría discursiva como teoría de la verdad y como teoría moral (en mi opinión, esta interpretación proporciona una mejor explicación del carácter incondicional que asociamos a nuestras

obligan a revisiones que vuelen a replantear cuestiones de fundamentación de la norma" (Habermas, J. "Corrección normativa versus verdad", op. cit., p. 286). En mi opinión, el recurso a los discursos de aplicación no puede ocultar el reconocimiento implícito de que la validez de las normas depende de condiciones objetivas que trascienden su justificación.

${ }^{29}$ Me referiré en todo momento a los discursos jurídicos de aplicación de normas desarrollados en sede judicial, no a los discursos legislativos o a cualesquiera otros de creación de normas jurídicas.

Revista de Direitos Fundamentais \& Democracia, Curitiba, v. 25, n. 3, p. 133-159, set./dez. 2020 
pretensiones de validez en los discursos teóricos y en los discursos morales, pero no es esta la cuestión que pretendo abordar aquí). Como vimos, la validez incondicional de nuestras paretensiones de verdad y de justicia se expresa en las propiedades que condensa la premisa de la unidad de respuesta correcta: (i) el uso binario de la oposición verdadero/falso y de la oposición justo/injusto (principio del tercero excluido), y (ii) el carácter permanente de la verdad y de la corrección moral. Puede decirse que la primera hace referencia al concepto de validez o corrección, mientras que la segunda viene determinada por el estándar de validez o corrección (truth-maker). Por otra parte, debe de haber quedado claro a estas alturas que, desde la perspectiva realista del discurso, la unidad de respuesta correcta no tiene un sentido epistémico, sino lógico, es decir, no se trata de un ideal contrafáctico al que nos acercamos a medida que crecen nuestras capacidades epistémicas, sino de un presupuesto lógico de nuestras prácticas argumentativas ${ }^{30}$ : si una proposición es verdadera, su negación no puede serlo (principio de no contradicción), y además es falsa (principio de bivalencia); del mismo modo, si una decisión o una norma que prohíbe una acción o una clase de acciones es justa, una decisión o una norma que califica esa acción o clase de acciones como obligatorias no puede ser igualmente justa y, por tanto, es necesariamente injusta ${ }^{31}$.

La traslación a las pretensiones de validez formuladas en el discurso jurídico de las propiedades que expresa la premisa de la unidad de respuesta correcta, (esto es, el uso binario de correcto/incorrecto y el carácter permanente de la corrección jurídica), tendría las siguentes implicaciones:

(i) Uso binario del par jurídicamente correcto/jurídicamente incorrecto. El uso binario de la noción de corrección jurídica significa que la validez no es una propiedad graduable de las pretensiones de corrección jurídica: o bien son válidas o bien no lo son. Esta tesis descansa en los siguientes postulados lógico-prácticos: (a) las modalidades deónticas de "prohibición", "obligación" y "permiso" son exhaustivas; y (b) cualquier modalidad deóntica es excluyente del resto ${ }^{32}$, como consecuencia del

${ }^{30} \mathrm{Al}$ menos, de aquellas prácticas argumentativas que no ponen en cuestión las nociones de verdad y justicia.

31 Al referirme al postulado de unidad de respuesta correcta como un "presupuesto lógico de la argumentación" no estoy afirmando que el principio de contradicción sea aplicable a las normas; y tampoco tiene que ver con el hecho de que ambas normas sean irrealizables simultáneamente. Lo que quiero expresar con ello es una concepción de la corrección práctica en la que dos normas contradictorias no pueden ser calificadas como justas.

32 No distingo aquí entre permisos positivos (a hacer algo) y negativos (a no hacer algo); la calificación deóntica del permiso atribuye al sujeto la facultad de realizar una conducta como de no realizarla, de manera que, en lo que aquí interesa, entre los distintos operadores cabrían únicamente relaciones de Revista de Direitos Fundamentais \& Democracia, Curitiba, v. 25, n. 3, p. 133-159, set./dez. 2020 
trasfondo valorativo implícito en la calificación de cualquier conducta ${ }^{33}$.

Las pretensiones de corrección jurídica tienen un sentido práctico: afirman que una decisión jurídica que califica una conducta como prohibida, obligatoria o permitida es correcta ${ }^{34}$. Podría objetarse que este uso binario difícilmente puede predicarse de las pretensiones de validez de la ciencia jurídica, dado que en muchas ocasiones no podemos determinar si una proposición normativa que describe el derecho válido es verdadera o falsa. Sin embargo, no hay razones para abandonar los principios de no contradicción y de bivalencia en el discurso jurídico de aplicación en tanto que éste está abierto a otros argumentos prácticos y sus condiciones de validez no se agotan en el derecho positivo ${ }^{35}$.

La premisa de la unidad de respuesta correcta está fuertemente arraigada en nuestras prácticas reales de aplicación del derecho ${ }^{36}$; no como una asunción metafísica o metaética, sino más bien, como sostiene Dworkin ${ }^{37}$, como una tesis de sentido común acerca de nuestro entendimiento del ejercicio legítimo de la coacción ${ }^{38}$. Carecería de sentido que un juez afirmara en una sentencia que su decisión "es una de las respuestas posibles entre otras igualmente correctas"; o, peor aún, que "es la segunda mejor opción entre otras posibles" (si fuera posible una afirmación en estos términos cuantitativos). La unidad de respuesta correcta implica, también, la existencia

contrariedad, es decir, que tomados dos de ellos es posible que ambos sean falsos o incorrectos, pero no que ambos sean verdaderos o correctos (vid. sobre las relaciones entre las distintas modalidades deónticas, véase, Echave, D. T. / Urquijo, M.E. / Guibourg, R. A. Lógica, proposición y norma, Astrea, Buenos Aires, 1988, pp. 127 y ss; Joerden, J. C. Logik im Recht. Grundlagen und anwendungbeispiele, Springer, Berlin/Heidelberg, 2005, pp. 200 y ss.).

33 Entiendo por trasfondo valorativo la ponderación de razones que justifican que una conducta sea permitida, obligatoria o prohibida. Tanto la obligación como la prohibición reflejan la existencia de razones para exigir una determinada conducta, por encima de la autonomía personal de los destinatarios de la norma. El permiso, en cambio, refleja o bien la irrelevancia práctica de la conducta, o bien el mayor peso de la autonomía personal frente a otras razones en relación con dicha conducta.

34 Alexy, R. Teoría de la argumentación jurídica, op. cit., p. 207. Otras cuestiones de carácter probatorio, interpretativo, así como la determinación de las consecuencias de una acción antijurídica (extensión de las penas, cantidades indemnizatorias, etc.), son complementarias de la decisión práctica.

35 De hecho, la unidad de respuesta correcta, tal y como aquí es entendida, no nos compromete necesariamente con una concepción holista de la justificación jurídica, sino con los postulados de exhaustividad y exclusión (en realidad, válidos para cualquier contexto práctico).

${ }^{36}$ Por cierto que no creo que esté igualmente arraigada -más bien al contrario- la tesis de la plenitud del derecho, según la cual las decisiones de los jueces están siempre y en todo caso determinadas por los materiales jurídicos.

37 Dworkin, R. "Pragmatism, Right Answers and True Banality", en Brint, M. / Weaver, W. (eds.) Pragmatism in Law and Society, Boulder, Westview Press, pp. 359-388, cita en p. 365. Para un análisis completo de la tesis dworkiniana de la respuesta correcta, vid. Bonorino, P. Objetividad y verdad en el derecho. Variaciones sobre un tema de Dworkin, Bogotá, Universidad Externado de Colombia, 2002, en especial el cap. II.

38 Vid. Habermas, J. "Reply", op. cit., pp. 1491-2 y 1502-3; Alexy, R. "La naturaleza de los argumentos sobre la naturaleza del derecho", en Id. El concepto y la naturaleza del derecho, trad. Carlos Bernal Pulido, Madrid/Barcelona/Buenos Aires, Marcial Pons, 2008, pp. 51-72, especialmente, pp. 66 y ss.

Revista de Direitos Fundamentais \& Democracia, Curitiba, v. 25, n. 3, p. 133-159, set./dez. 2020 
de un orden de prevalencia entre las distintas respuestas posibles en los casos difíciles: la segunda mejor respuesta no es una respuesta correcta. Las dificultades (límites epistémicos y temporales de los procesos reales de toma de decisiones) para alcanzar la respuesta correcta no ponen en cuestión la tesis del sentido común; simplemente hacen que la decisión esté sujeta a revisión ante la aparición de nuevos elementos de juicio (como el resto de decisiones, por otra parte) ${ }^{39}$.

(ii) Carácter permanente de la corrección jurídica. El carácter permanente de la verdad o de la corrección moral significa que son propiedades que las proposiciones o las normas no pueden perder; o dicho de otro modo, cualquier modificación de las mismas sólo puede explicarse a partir de la falibilidad de nuestras prácticas de justificación. Para admitir la falibilidad, incluso en condiciones ideales, de los discursos teóricos y morales nos comprometemos con una presuposición realista, de manera que las condiciones necesarias y suficientes de validez incorporan circunstancias objetivas independientes de nuestras creencias, percepciones y preferencias; es esta presuposición realista, que remite a un estándar objetivo, la que expresa el carácter permanente de la verdad y la justicia del que carece la justificación. Del mismo modo, el carácter permanente de la corrección se manifiestaría en el contexto jurídico si fuera concebible que una decisión jurídica justificada puediera ser incorrecta.

Es un hecho que los tribunales superiores casan las decisiones de los tribunales inferiores; que, en ocasiones, los tribunales se separan de los precedentes judiciales; e, igualmente, que las decisiones de los tribunales son discutidas por la doctrina y por la opinión pública en general. También es un hecho que, con más o menos acierto, suelen darse razones de por qué se modifica una sentencia de un tribunal inferior, se abandona una línea jurisprudencial o se critica una decisión judicial. Todo ello indica que la aplicación de normas jurídicas se concibe como una actividad racional, pero también falible. En muchos casos, los errores consisten en el incumplimiento de normas procesales, desde las garantías fundamentales en el proceso, hasta cuestiones de competencia territorial, plazos, etcétera; otras veces, consistirán en cuestiones de hecho; y, en otros casos, el error afectará al contenido de la decisión. Cuáles sean las explicaciones de estos errores que una teoría de la

39 Se ha objetado a esta tesis del sentido común que la creencia en respuestas correctas en el ámbito prático no es más que un error generalizado. Esta objeción, aunque le afecta directamente, excede con mucho el asunto que aquí estamos tratando; pone en cuestión el sentido de nuestras prácticas argumentativas y, con ello, el sentido de muchas de las instituciones jurídicas, sociales y políticas sobre las que está construida nuestra civilzación. No creo que sea posible imaginar cómo serían las cosas en un mundo fundado en el escepticismo.

Revista de Direitos Fundamentais \& Democracia, Curitiba, v. 25, n. 3, p. 133-159, set./dez. 2020 
corrección jurídica proporciona, lo cual depende de qué se entienda por jurídicamente correcto, permitirá dilucidar si se trata o no de una propiedad permanente.

Antes de considerar una teoría particular, voy a distinguir en términos generales entre dos concepciones de la corrección jurídica: una concepción procedimental y una concepción realista. Mientras la primera es una tesis reduccionista, para la cual justificación y corrección son nociones equivalentes e intercambiables, la segunda no lo es, y para ésta tiene pleno sentido afirmar que una decisión está justificada pero es incorrecta, porque, para esta segunda concepción, la corrección jurídica no es completamente dependiente de un procedimiento, sino que depende de circunstancias objetivas.

Quien sostenga una concepción procedimental debe mostrar que los criterios de justificación de las decisiones jurídicas agotan el sentido de la corrección jurídica. Una noción no circular ${ }^{40}$ de justificación jurídica debe hacer referencia a las prácticas de justificación de la comunidad jurídica, ya se trate de las reglas y formas del discurso jurídico $^{41}$ o de otro principio o procedimiento justificatorio. Si la concepción procedimental es correcta, el discurso jurídico (u otro principio o prcedimiento justificatorio) garantiza la corrección de la decisión jurídica, de manera que la única explicación disponible de la existencia de decisiones erróneas es el cumplimiento defectuoso del procedimiento o la inaplicación del principio correspondiente (lo cual no está exento de probelmas) ${ }^{42}$.

${ }^{40}$ La definición de la justificación jurídica en términos de corrección resulta circular si no se especifica en qué consiste la justificación.

41 Vid. Alexy, R. Teoría de la argumentación jurídica, op. cit., pp. 285 y ss.

42 Hay dos supuestos en los que se ponen de manifiesto las limitaciones explicativas de una concepción procedimental o reduccionista de la corrección jurídica: 1) que dos decisiones incompatibles puedan aparecer como jurídicamente justificadas según el principio o el procedimiento de que se trate (problema de la pluralidad de respuestas correctas); y 2) que una decisión justificada jurídicamente resulte inaceptable (problema de la irrazonabilidad). Ambos supuestos tienen difícil acomodo dentro de una concepción procedimental. El primer supuesto únicamente es concebible como problema si se asumen los postulados lógico-prácticos de exhaustividad y exclusión de las modalidades deónticas, o sea, que una de las dos decisiones es necesariamente incorrecta. Sin embargo, nada impide que un procedimiento o principio de justificación permita que el número de respuestas justificadas $-\mathrm{y}$, por ende, correctas- sea mayor a uno. Si esto es así, la práctica justificatoria en cuestión funciona como un criterio negativo de corrección, que únicamente permite distinguir entre respuestas justificadas y respuestas que no lo están; como se ha apuntado con anterioridad, éste sería un criterio débil o deficitario, incapaz de discriminar racionalmente entre las distintas respuestas justificadas. Una pretensión de corrección en estos términos, sólo puede ser una pretensión devaluada, que no excluye la corrección de una decisión incompatible con aquella a la que se adscribe la pretensión de corrección. Más claro aún resulta en relación con el segundo problema, el de la irrazonabilidad, ya que, en el marco conceptual de una concepción procedimental, los resultados del procedimiento que agota el significado de la corrección jurídica no pueden ser incorrectos, por definición. Esto supone, o bien una renuncia a un concepto fuerte de corrección, o bien algún tipo de compromiso con la infalibilidad de nuestras capacidades epistémicas o de nuestras prácticas de justificación, o de ambas, en determinadas condiciones ideales.

Revista de Direitos Fundamentais \& Democracia, Curitiba, v. 25, n. 3, p. 133-159, set./dez. 2020 
Por su parte, quien sostenga una concepción realista debe asumir algún criterio objetivo de corrección que trascienda las prácticas justificativas.

\subsection{Las condiciones necesarias y suficientes de la corrección jurídica.}

La conclusión a que se llega en el apartado anterior es que la corrección jurídica es una pretensión de validez incondicional si su significado implica: 1) los postulados de exhaustividad y exclusión, y 2) alguna circunstancia objetiva como condición necesaria y suficiente de validez.

Como el concepto de corrección moral o justicia, el de corrección jurídica es un concepto ampliamente discutido. En este apartado me limitaré a considerar algunas de las posiciones más relevantes dentro del marco de las teorías de la argumentación jurídica influidas por la teoría discursiva cuyas condiciones necesarias y suficientes de la corrección jurídica difieren sustancialmente.

En origen, las teorías de la argumentación jurídica surgen como un intento de superación de la dicotomía "determinismo-decisionismo" en la aplicación del derecho ${ }^{43}$, negando la tesis central de ambas posiciones extremas: ni todas las decisiones jurídicas están predeterminadas por los materiales jurídicos de que dispone el juzgador; ni son meros actos de voluntad que escapan a toda posibilidad de control racional. Igualmente, ponen de manifiesto la necesidad de que las respuestas del derecho sean aceptables. Por estos motivos, la mera referencia al derecho vigente puede resultar insuficiente para decidir una controversia jurídica y es aquí donde las teorías de la argumentación proponen criterios de validez de las decisiones jurídicas.

Uno de estos criterios es el principio regulativo del razonamiento jurídico de Aulis Aarnio:

\footnotetext{
"Trata de alcanzar una solución y justificación tales para los casos difíciles que la mayoría de los miembros que piensan racionalmente en la comunidad jurídica puedan aceptar"44.
}

Este principio regulativo es el corolario de una teoría de la argumentación jurídica que parte de un relativismo metaético. Coherentemente, Aarnio rechaza

\footnotetext{
43 Neumann, U. Juristische Argumentationslehre, op. cit., p. 2; Bäcker, C. Begründen und Entscheiden, op. cit., pp. 25 y ss.

${ }^{44}$ Aarnio, A. "La respuesta correcta única y el principio de la mayoría", en Id. Derecho, racionalidad y comunicación social. Ensayos sobre Filosofía del Derecho, trad. Pablo Larrañaga, México D.F., Fontamara, 1995, pp. 47-67, cita en p. 67.

Revista de Direitos Fundamentais \& Democracia, Curitiba, v. 25, n. 3, p. 133-159, set./dez. 2020
} 
explícitamente la unidad de respuesta correcta ${ }^{45}$ y el carácter cognitivo del principio regulativo del razonamiento jurídico ${ }^{46}$. Asumiendo que no es posible el consenso racional entre personas que no comparten la misma formadevida (en el sentido de Wittgenstein $)^{47}$, la mejor decisión posible -la que maximiza las expectativas de certeza jurídica ${ }^{48}$ - ante un desacuerdo interpretativo es aquella más ampliamente aceptada por los miembros de la comunidad que piensan racionalmente, esto es, la mejor decisión posible es aquella susceptible de aceptabilidad racional.

Este principio regulativo expresa claramente una concepción procedimental de la corrección jurídica, que no incluye ninguna circunstancia objetiva independiente de nuestras prácticas de justificación como condición necesaria y suficiente de la validez de las decisiones jurídicas. Aarnio no atribuye a la corrección jurídica un carácter incondicional; aquella es una función dependiente del resultado del procedimiento. "Ser la opinión dominante o mayoritaria" es una propiedad que los enunciados pueden perder sin que esa modificación deba explicarse como la corrección de un error, sino como la pérdida de vigencia social de determinados valores y convicciones morales. La

45 En realidad, la interpertación de la unidad de respuesta correcta expuesta en este trabajo, basada en los postulados de exhaustividad y exclusión de las modalidades deónticas en el razonamiento práctico, y la tesis rechazada por Aarnio difieren en algún punto relevante. Para el autor finlandés, la premisa de la unidad de respuesta correcta tiene esencialmente un sentido ideológico, que pretende evitar la vaguedad y arbitrariedad a que se vería abocada la práctica jurídica si reconociéramos la posibilidad de dos o más respuestas posibles para un mismo caso. Por otro lado, la aceptación de la unidad de respuesta correcta implicaría dos tesis: una tesis ontológica, que afirma la existencia de respuestas correctas en el derecho, y una tesis epistemológica y metodológica, según la cual dichas respuestas son accesibles. Si la tesis ontológica es equiparable a un postulado de deducibilidad a partir de los materiales jurídicos disponibles para el juzgador, no es dificil de rechazar, pero resulta una afirmación gratuita a estas alturas; el problema radica, más bien, en la extensión del derecho, porque si los principios morales que el juez incorpora a su razonamiento son también derecho, en ese caso, la negación de la tesis ontológica es más discutible. En cuanto a la tesis epistemológica, Aarnio se pregunta cuándo el intérprete puede saber que ha encontrado la respuesta correcta. Si este saber tiene un carácter final y definitivo, no estamos (ni creo que lo vayamos a estar en el futuro) en condiciones de afirmar algo así, ni siquiera en un discurso en condiciones ideales; a lo más que se puede aspirar es a una justificación tal que nos permita tener por correcta una respuesta, pero el reconocimiento de nuestras limitaciones en una situación epistémica dada, es decir, de nuestra falibilidad, no implica necesariamente la renuncia a la corrección, ni la aceptación contraintuitiva de la pluralidad de respuestas correctas (vid. Aarnio, A. Lo racional como razonable. Un tratado sobre la justificacion jurídica, trad. Ernesto Garzón Valdés, Madrid, Centro de Estudios Constitucionales, 1991, pp. 209 y ss.; Aarnio, A. "La respuesta correcta única y el principio de la mayoría", op. cit.).

46 "El principio regulativo no da ninguna autoridad para proclamar: "yo estoy en lo correcto". El principio sólo trata de provocar a quien toma la decisión a que lleve a cabo una justificación racional" ("La respuesta correcta única y el principio de la mayoría", op. cit., p. 67).

47 Vid. Wittgenstein, L. Sobre la certeza, trad. J. L. Prados y V. Raga, Barcelona, Gedisa, 1997; Aarnio, A. "Linguistic Philosophy and Legal Theory", Rechtstheorie, Beiheft 1, pp. 17-41; Id. Lo racional como razonable, op. cit., pp. 279 y ss.

48 El concepto de "certeza jurídica", central para su teoría de la argumentación, tiene en Aarnio una doble dimensión, formal (racionalidad de la decisión) y material (razonablilidad de la decisión); vid. entre otros muchos, Aarnio, A. Lo racional como razonable, op. cit., pp. 26 y ss. Una evaluación crítica de las tesis de Aarnio puede verse en Comanducci, P. "Aarnio and the Problem of Legal Certainty". Rechtstheorie 26 (1995), 27-44.

Revista de Direitos Fundamentais \& Democracia, Curitiba, v. 25, n. 3, p. 133-159, set./dez. 2020 
aceptabilidad racional, por tanto, es condición necesaria y suficiente de la validez de las decisiones jurídicas. Con ello, la aceptabilidad racional se erige en el concepto nuclear de esta teoría de la argumentación jurídica.

Una concepción distinta de la corrección jurídica puede encontrarse en el planteamiento de Alexy, aunque esto no resulte evidente en una primera aproximación. En su Teoría de la argumentación jurídica, Alexy sostiene que la pretensión de corrección formulada en el discurso jurídico se refiere a que los enunciados normativos "puedan ser fundamentados racionalmente en el marco del ordenamiento jurídico vigente" 49 . Igualmente, sostiene que las reglas y formas del discurso jurídico constituyen "un criterio de corrección para las decisiones jurídicas" 50 . Al reducir las condiciones necesarias y suficientes de la corrección jurídica a la fundamentación racional conforme a las reglas y formas del discurso jurídico ${ }^{51}$, Alexy adopta, al menos aparentemente, una concepción procedimental de corrección para el discurso jurídico ${ }^{52}$.

Hay, sin embargo, una tesis central en la obra de Alexy, la tesis de la naturaleza dual del derecho, que ha ido adquiriendo visibilidad paulatinamente, y que avalaría, en mi opinión, una interpretación realista de su teoría del discurso jurídico. Según la tesis de la naturaleza dual, el derecho presenta una dimensión ideal, expresada en la pretensión de corrección, y una dimensión real, que se manifiesta en la eficacia (coerción / uso de la fuerza), pero también en el valor de la seguridad jurídica.

En la Teoría de la argumentación jurídica, la tesis de la naturaleza dual ni siquiera es formulada explícitamente, aunque esta implícita en las reglas de uso de los argumentos interpretativos en el discurso jurídico. Estas reglas establecen las

${ }^{49}$ Alexy, R. Teoría de la argumentación jurídica, op. cit., p. 274.

50 Alexy, R. Teoría de la argumentación jurídica, op. cit., p. 279.

51 Sobre la equiparación de procedimiento y corrección, vid. Alexy, R. "La idea de una teoría proesal de la argumentación jurídica", en Garzón Valdés, E. (comp.), Derecho y Filosofía, trad. Carlos de Santiago, Barcelona/Caracas, Alfa, 1985, pp. 43-57.

${ }^{52}$ Alexy también admite que "un juicio sobre la corrección de una decisión (...) tiene siempre un carácter provisional, es decir, puede ser refutado" 52 . Este carácter provisional de los resultados del discurso no es, de ninguna manera, un obstáculo insalvable para una teoría procedimental de la corrección. Ahora bien, si la teoría tiene, además, pretensiones cognoscitivas, es decir, si pretende ser una teoría de la corrección jurídica, entonces debe proporcionar una explicación de la relación entre ese saber práctico y el procedimiento, así como una explicación coherente -esto es, en términos procedimentales- de la falibilidad de los resultados de los discursos prácticos, que hace que sean provisionales. Y, sin duda, este es el tipo de explicación que Alexy proporciona cuando, en relación con el discurso práctico general, afirma que su incapacidad para garantizar acuerdos definitivos e irrevocables "radica en el hecho de que especialmente las reglas de razón (...) [las reglas que regulan la participación universal (inclusión), libre e igual (simetría) en el discurso] sólo pueden cumplirse parcialmente" (Alexy, R. Teoría de la argumentación jurídica, op. cit., p. 201; subrayado JMCA).

Revista de Direitos Fundamentais \& Democracia, Curitiba, v. 25, n. 3, p. 133-159, set./dez. 2020 
relaciones de precedencia prima facie entre los distintos argumentos institucionales (lingüísticos, genéticos y sistemáticos), así como la apertura el discurso jurídico a argumentos prácticos generales o sustantivos -(morales, éticos-políticos)- que pueden revertir las relaciones de jerarquía entre los argumentos institucionales e incluso acabar imponiéndose a éstos 53 .

La tesis de la naturaleza dual del derecho aparece de un modo mucho más evidente en la definición formulada por Alexy en El concepto y la validez del derecho. En ella, sostiene que pertenecen al derecho "los principios y otros argumentos normativos en los que se apoya el procedimiento de la aplicación del derecho y/o tiene que apoyarse a fin de satisfacer la pretensión de corrección". La incorporación en esta última cláusula de elementos empíricos ("se apoya") y normativos ("tiene que apoyarse") "expresa -dice Alexy- el juego de las dimensiones real e ideal de la aplicación del derecho" 54 .

No ha sido hasta la reciente discusión acerca de la naturaleza del derecho que la tesis de la dualidad ha sido definitivamente explicitada ${ }^{55}$. En este marco, Alexy ha calificado la pretensión de validez de los discursos jurídicos como una pretensión de corrección "de segundo nivel"; y es en esta calificación donde cabe hacer una lectura realista de la corrección jurídica. Como se ha dicho más arriba, la dimensión ideal del derecho corresponde a la corrección sustantiva de las normas y decisiones jurídicas; mientras que la dimensión real hace referencia al factor institucional o positivo del derecho. La reconciliación de ambas dimensiones pasa por la distinción de dos niveles de corrección: en el primer nivel (first-order correctness), la corrección tiene un sentido ideal, que se identifica con la justicia; en el segundo nivel (second-order correctness), la corrección tiene un sentido comprehensivo, y se refiere tanto a la dimensión ideal como a la dimensión real, esto es, tanto a la justicia como a la eficacia y a la seguridad

53 Se trata concretamente de las reglas (J.7), (J.8) y (J.9) (Alexy, R. Teoría de la argumentación jurídica, op. cit., pp. 239 y s.); vid. también una reformulación de (J.7) en Alexy, R., "Juristischelnterpretation", en Id. Recht, Vernunft, Diskurs, op. cit., pp. 71-92, aquí p. 90.

${ }^{54}$ Alexy, R. "El concepto y la validez del derecho", en Id. El concepto y la validez del derecho, op. cit., pp. 13-130, cita en p. 126. La naturaleza dual del derecho estaría igualmente en otros pasajes del texto; por ejemplo, en el rechazo de la tesis de la irradiación, según la cual la invalidez de las normas sustantivas básicas de un sistema jurídico supone la pérdida de validez de todas las normas típicas del sistema jurídico; a este respecto, Alexy sostiene que "[l]a seguridad jurídica quedaría muy afectada si una norma que se encuentra por debajo del umbral de la injusticia extrema perdiera su carácter jurídico por participar de alguna manera en el contenido de injusticia del sistema total. (...) En el caso de la injusticia extrema, el desplazamiento del principio de la seguridad jurídica es todavía aceptable" (pp. 70-71).

55 Vid. los trabajos de Alexy incluidos en el ya citado El concepto y la naturaleza del derecho, así como Raz, J. / Alexy, R. I Bulygin, E., Una discusión sobre la teoría del derecho, trad. Hernán Boubier, Paula Gaido y Rodrigo Sánchez Brígido, Madrid, Marcial Pons, 2007; pp. 87-98; también, "The Dual Nature of Law", Ratio luris 23 (2010), pp. 167-182.

Revista de Direitos Fundamentais \& Democracia, Curitiba, v. 25, n. 3, p. 133-159, set./dez. 2020 
jurídica. Así, la corrección de segundo nivel conecta ambas dimensiones: el principio de justicia y el principio de seguridad jurídica. ¿Qué ocurre si ambos principios colisionan? El establecimiento de una relación absoluta de prioridad entre ambos principios resulta incompatible con la naturaleza dual del derecho (también con la racionalidad discursiva), que, por el contrario, exige que entre ambos principios se de una relación de proporcionalidad. La corrección de segundo nivel, afirma Alexy, "es una cuestión de ponderación"56; o, dicho de otro modo, es una cuestión de razonabilidad ${ }^{57 .}$

Entendida como corrección de segundo nivel, la corrección jurídica significa proporcionalidad entre la dimensión ideal y la dimensión real del derecho, o, simplificando algo las cosas, proporcionalidad entrelos principios de justicia y seguridad jurídica. Si la corrección jurídica consiste en esta relación de proporcionalidad, entonces "fundamentar racionalmente en el marco del ordenamiento jurídico vigente" significa afirmar que una determinada decisión jurídica expresa una relación de proporcionalidad entre la justicia y la seguridad en el marco de un determinado ordenamiento jurídico vigente. En otras palabras, si esta decisión es o no razonable. Este es el contenido de la pretensión de validez formulada en los discursos jurídicos.

Ahora bien, la cuestión es que con ello se ha introducido ya una condición objetiva, independiente de nuestras prácticas de justificación, como condición necesaria y suficiente de la validez de las decisiones jurídicas. Al definir la corrección jurídica como una relación de equilibrio o proporcionalidad entre la dimensión ideal y real o entre dos principios morales (seguridad y justicia), entran en juego los intereses generalizables. De la ponderación de ambos principios, en caso de que entren en conflicto, resultará que, en determinadas circunstancias, está justificado el sacrificio de intereses protegibles - pongamos por caso, la seguridad jurídica y todos aquellos intereses derivados, empezando por la autonomía individual- en virtud del mayor grado de realización de otros intereses -aquellos que tengan que ver con la justicia de la decisión- igualmente protegibles. En tanto que los intereses generalizables son concebidos como "hechos" y no como una construcción resultante de un proceso argumentativo (ni siquiera en condiciones ideales), la noción de justicia tiene un sentido objetivo que trasciende nuestras prácticas de justificación. E igualmente ocurre con la

56 "The Dual Nature of Law", op. cit., p. 174.

57 "La fusión de lo real y lo ideal es la esencia de la idea de la razonabilidad del derecho" (Alexy, R. "The Reasonableness of Law", en en Bongiovani, G. / Sartor, G. / Valentini (eds.), Reasonableness and Law, Dordrecht / Heidelberg / London / New York, Springer, 2009, pp. 5-15, cita en p. 13). La conexión entre ponderación y razonabilidad la toma Alexy de Neil MacCormick (vid. MacCormick, N., "Retórica y Estado de Derecho", Isegoría 21 (1999), pp. 5-21; Id. Rhetoric and the Rule of Law: A Theory of Legal Reasoning, Oxford / New York, OUP. 2005, cap. 9).

Revista de Direitos Fundamentais \& Democracia, Curitiba, v. 25, n. 3, p. 133-159, set./dez. 2020 
razonabilidad de la decisión jurídica. La razonabilidad, por tanto, es una presuposición formal que da sentido a las pretensiones de validez formuladas en los discursos jurídicos, del mismo modo en que presuponemos la existencia de un único mundo objetivo igual para todos y de intereses generalizables en los discursos teóricos y morales, respectivamente.

Así entendida, la concepción de la corrección jurídica de Alexy se aproxima bastante a una concepción realista o no reduccionista. El concepto central de esta teoría de la argumentación jurídica no es el de procedimiento, sino el de razonabilidad, que condensa las condiciones necesarias y suficientes de la validez jurídica. Si esta interpretación es atinada, la pretensión de corrección formulada en los discursos jurídicos no se agota en la pretensión de justificación conforme a las reglas y formas del discurso jurídico, sino que contiene también una pretensión de validez incondicional, de naturaleza proposicional, no epistémica, expresada en la idea de razonabilidad. La pretensión de justificación tiene necesariamente un carácter procedimental, pero la pretensión de corrección jurídica, entendida como razonabilidad, es una noción realista, en el sentido señalado aquí.

\subsection{La justificación de las pretensiones de validez jurídica.}

En los discursos jurídicos no basta con afirmar que una decisión es correcta; hemos de ser capaces de fundamentar nuestras pretensiones de validez. Entre la justificación y la validez jurídicas existe una relación interna similar a la existente entre la aceptabilidad racional y la verdad o entre aquella y la justicia. Sin embargo, la necesidad de justificación -motivación- de las peticiones de parte y las decisiones judiciales no es únicamente una exigencia pragmática vinculada a nuestros usos lingüísticos, sino también una exigencia jurídico-positiva de los ordenamientos jurídicos modernos. Esta circunstancia, no obstante, no representa una objeción a la interpretación realista del discurso jurídico. La exigencia de motivación tiene más que ver con la legitimidad de la decisión que con su corrección; o dicho de otro modo, la motivación no garantiza la infalibilidad de quien toma la decisión, sino la ausencia de arbitrariedad. Además, el hecho de que una misma decisión jurídica, esto es, la calificación de una conducta como prohibida, permitida u obligatoria, pueda ser motivada por argumentos distintos habla a favor de la distinción conceptual entre la justificación y la corrección de una decisión jurídica. 


\section{CONCLUSIÓN.}

Las pretensiones de validez que formulamos con nuestras afirmaciones, ya sean pretensiones de verdad, cuando describimos de estados de cosas, ya sean pretensiones de corrección, cuando afirmamos que una acción debe ser realizada, omitida o ninguna de estas cosas (en cuyo caso estaría permitida), tienen un carácter incondicional cuando la noción a la que se refiere dicha validez -verdad, justiciadepende de circunstancias objetivas. La asunción de estas circunstancias objetivas como presupuestos realistas de carácter formal -que el mundo es uno y el mismo para todos o la existencia de intereses generalizables- determina la autocomprensión de nuestras prácticas argumentativas. Podría negarse que el mundo es uno y el mismo para todos o que existan intereses generalizables, pero, entonces, las pretensiones de verdad o de corrección, así como los discursos en los que se resuelven, perderían necesariamente su sentido cognoscitivo.

La identificación y asunción de estos presupuestos realistas de carácter formal no resulta problemático en los discursos teóricos y, como consecuencia de ello, la teoría consensual de la verdad en sentido estricto queda completamente descartada. La identificación y asunción de presupuestos similares en al ámbito práctico resulta, sin embargo, mucho más discutida. Aquí he intentado mostrar, siguiendo la interpretación realista o no reduccionista propuesta por Cristina Lafont para la ética discursiva, que sólo con alguna asunción de este tipo, como la existencia de intereses generales en los discursos morales, resulta posible una explicación coherente de la racionalidad discursiva y de la objetividad de sus resultados. Esta explicación pasa, necesariamente, por evitar compensar los déficits de nuestras prácticas de justificación con una inadvertida apelación a la infalibilidad. Únicamente una interpretación realista permite explicar por qué el compromiso con la racionalidad discursiva de nuestras pretensiones de corrección moral no supone un compromiso con la incorregibilidad, esto es, por qué ser racional no significa ser infalible, ni siquiera en condiciones ideales.

Tampoco en el contexto jurídico hay acuerdo acerca de cuáles sean las condiciones necesarias y suficientes de validez, de manera que no puede afirmarse categóricamente que las pretensiones de corrección que formulamos en los discursos jurídicos tengan el carácter incondicional que atribuimos a la verdad o a la justicia. El 
contraste entre las posturas de Aarnio y Alexy muestra hasta qué punto esto es así. Ahora bien, si se afirma, como hace Alexy cuando define la corrección jurídica como una corrección de segundo nivel, que la pretensión de corrección expresa una relación de proporcionalidad entre la dimensión real (seguridad jurídica) y la dimensión ideal (justicia) del derecho, entonces, se atribuye a la corrección jurídica un carácter incondicional. Este carácter incondicional supone la separación conceptual entre la validez o corrección y la justificación; mientras que la primera depende en última instancia de circunstancias objetivas, la segunda es una cuestión de aceptabilidad racional.

La extensión de la interpretación realista de la teoría o no reduccionista de la ética discursiva al contexto jurídico supone que el concepto central de una teoría de la argumentación jurídica que responda a la descripción anterior no es ni el consenso, ni el procedimiento, que serían criterios de justificación, sino la idea expresada por la corrección de segundo orden o razonabilidad. Ciertamente, sólo atendiendo a su justificación estamos en condiciones de afirmar que la decisión de un tribunal es correcta o no lo es. No hay otras vías de acceso a la validez; pero, en la medida en que esta validez dependa de circunstancias objetivas que pueden ser incorrectamente apreciadas por los participantes en un discurso, la justificación no es condición necesaria ni suficiente de la corrección jurídica.

Recebido em 13/11/2020

Aprovado em 02/12/2020

Received in 13/11/2020

Approved in 02/12/2020 